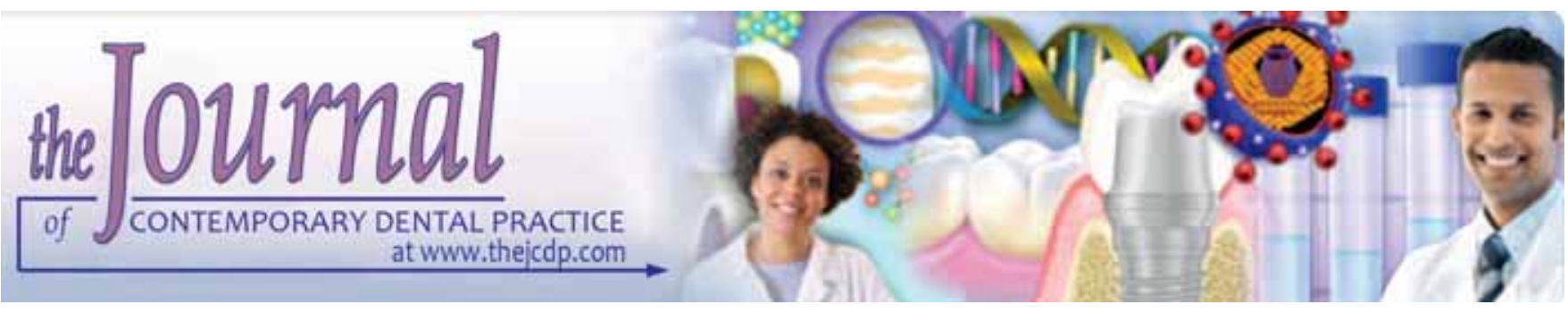

\title{
Definition and Endodontic Treatment of Dilacerated Canals: A Survey of Diplomates of the American Board of Endodontics
}

\author{
Nafiseh Dastmalchi, Zeinab Kazemi, Siroos Hashemi, Ove A Peters, Hamid Jafarzadeh
}

\section{ABSTRACT}

Aim: To gather data from Diplomates of the American Board of Endodontics regarding treatment of dilacerated canals.

Materials and methods: A questionnaire addressing definition, endodontic treatment procedures and prognosis was constructed and distributed via e-mail to 708 Diplomates of the American Board of Endodontics. Data from 150 respondents, a $21 \%$ response rate, were collected by using a Web-based interface. For statistical analysis, Chi-square tests were used.

Results: More than 25\% of respondents believed that a dilacerated root should have a curvature $>40^{\circ}$. One-visit treatment is the best therapeutic approach and transportation is the most likely complication in preparation of these canals. A crown-down technique, watch-winding motion and a master apical file \# 25 are the best choices for preparation of these canals. Any warm obturation technique is preferred over lateral compaction by most respondents.

Conclusion: A crown-down technique for root canal preparation and a thermoplastic obturation technique are recommended for canals whose curvature is more than $40^{\circ}$. The prognosis of the treatment of these canals is judged not lower than normal canals.

Clinical significance: Crown-down technique and thermoplastic obturation are recommended for dilacerated canals.

Keywords: Dilaceration, Endodontic treatment, Root curvature, Survey study.

How to cite this article: Dastmalchi N, Kazemi Z, Hashemi S Peters OA, Jafarzadeh H. Definition and Endodontic Treatment of Dilacerated Canals: A Survey of Diplomates of the American Board of Endodontics. J Contemp Dent Pract 2011;12(1):8-13.

Source of support: Nil

Conflict of interest: None declared

\section{INTRODUCTION}

A straight root with straight canal is rarely seen and most canals have a plane of curvature throughout their length; however, the degree of curvature varies between different roots/canals, some of them may have severe curvatures. ${ }^{1}$
The term 'dilaceration' was first used in 1848 by Tomes. ${ }^{2}$ This term is defined as a bend in the linear relationship of a crown of a tooth to its root. ${ }^{3-6}$ Some authors ${ }^{7,8}$ believe that a tooth has dilaceration if there is $\mathrm{a} \geq 90^{\circ}$ angle along the axis of the root, whereas Chohayeb $^{9}$ defined it as a deviation from the normal axis of the tooth of $\geq 20^{\circ}$ in the apical area. However, the criteria have not been defined precisely for considering a root as dilacerated.

Dilaceration is one of the factors that may complicate the endodontic treatment so when attempting to perform root canal therapy; dentist should use great care to avoid mishaps in these teeth. ${ }^{1}$ Although some researches have been done on dilaceration, the body of scientific literature lacks complete information on materials or techniques which could facilitate the endodontic treatment of them.

A questionnaire survey is a suitable way for collecting data about potential problems which can help problem solving in daily practice. No questionnaire survey has been undertaken in the entire world regarding endodontic treatment of dilacerated canals. Therefore, the purpose of this survey was to retrieve data from Diplomates of the American Board of Endodontics (ABE) regarding definition and endodontic treatment of dilacerated canals.

\section{MATERIALS AND METHODS}

An online questionnaire (by using a Question Pro.com Web link) was constructed with 16 questions addressing definition, complications, access cavity preparation, estimating of the working length, the best method of canal preparation and obturation, the best size of master apical file (MAF), preferred instruments/systems and prognosis of dilacerated canals. For assessment of the reliability and validity of the questionnaire, a pilot questionnaire was 
delivered to 11 local academic endodontists. According to its feedback, one question was removed and some of the questions were revised. Finally, the questionnaire included 15 questions.

All questions were constructed by using check boxes and an option for free-text comments at the end of the questionnaire. Selection of more than one answer was allowable. The questions were based on the experience of the authors in addition to the information gathered from recent review ${ }^{1}$ and endodontic textbooks.

The online survey was sent to Diplomates of the ABE. They included 782 persons but 74 of them did not have e-mail addresses and so their names were removed from the list. Also, 23 of these 782 persons had two e-mail addresses and both of their addresses were used for this survey. The names and the addresses of potential subjects were gathered from the membership directory published by the American Association of Endodontists (AAE) and also by searching the internet.

Via this e-mail, the participants informed that the survey was a research project. For obtaining unbiased data, identification of the respondents was not mandatory. One reminder e-mail was sent to the ABE members who had not completed the survey after 3 weeks. The average time taken to complete the survey determined by checking how long the Web connection was open.

Statistical analysis was performed by using SPSS version 15. Findings were analyzed by Chi-square test where the critical significance was set at $\mathrm{p}<0.05$.

\section{RESULTS}

Valid responses were received from 150 ABE Diplomates, indicating a $21 \%$ response rate. The average time taken to complete the survey was 4 minutes.

\section{At what minimum degree of curvature do you} consider a root to be dilacerated?

Of the respondents, $25 \%$ stated that a dilacerated root should have a curvature more than $40^{\circ}$. There was a significant difference between this choice and other choices $(p=0)$ (Fig. 1).

2. Which of the following is the most likely complication in preparation of dilacerated canals?

Thirty-six percent of respondents considered transportation as the most likely complication in preparation of these canals. Twenty-two percent considered ledge, 15\% instrument breakage, 15\% blockage, $5 \%$ zip, $2 \%$ perforation and $2 \%$ other complications. There was a significant difference between transportation and other choices $(\mathrm{p}=0)$.

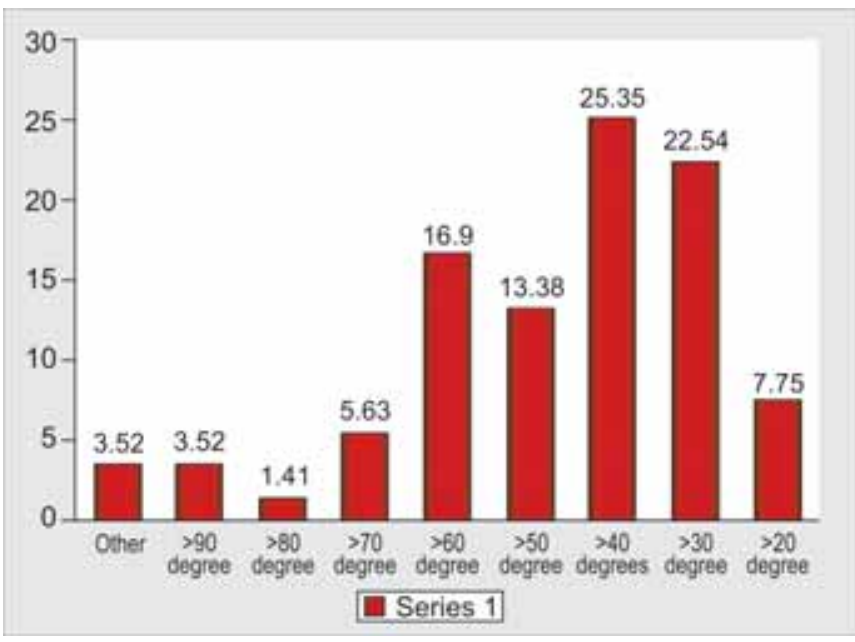

Fig. 1: At what minimum degree of curvature do you consider a root to be dilacerated?

3. Do you prefer to treat these canals in one appointment or to have multiple visit treatment?

Seventy-one percent of the ABE members considered one-visit treatment as the best therapeutic approach for treating dilacerated canals, whereas the others considered two-visit approach. This difference was significant $(p=0)$.

4. What is the most difficult stage of endodontic treatment of these canals?

Eighty-eight percent of respondents believed that root canal preparation is the most difficult stage in treating these canals. Five percent considered obturation, $4 \%$ access cavity preparation and $1 \%$ other procedures. There was a significant difference between root canal preparation and other choices $(\mathrm{p}=0)$.

5. Does the access cavity preparation in these canals need any modification?

Fifty-seven percent of respondents answered positively to this question; however, the difference between positive response group and negative ones was not significant $(\mathrm{p}>0.05)$.

6. What is the best technique of estimating the working length in these canals?

Sixty-nine percent of the ABE Diplomates stated that the best technique of estimating working length in dilacerated canals was application of electronic apex locator. Fifteen percent chose conventional radiography, $10 \%$ digital radiography and $4 \%$ other systems. There was a significant difference between apex locator and other choices $(\mathrm{p}=0)$.

7. What is the best method for preparation of these canals?

Fifty-six percent of respondents chose the crown-down technique as the best method for preparing these canals. 
There was a significant difference between this choice and other choices ( $p=0$ ) (Fig. 2).

8. What is the best size of master apical file size for preparation of these canals?

Thirty-eight percent of respondents selected \#25 as the best size of MAF for preparation of these canals. There was a significant difference between this choice and other choices ( $p=0$ ) (Fig. 3).

9. Which kind of instruments do you use in preparation of these canals?

Twenty-six percent of respondents stated that they use full rotary files for preparation of dilacerated canals; however, there was no significant difference between this choice and other ones ( $p>0.05$ ) (Fig. 4).

10. In a case with dilacerated $\operatorname{root}(\mathrm{s})$, which of the instrumentation systems do you prefer?

Forty-three percent of respondents preferred watchwinding motion for instrumentation of dilacerated canals. Seventeen percent chose clockwise rotation, 11\% counter-clockwise rotation, $11 \%$ push and pull motion,

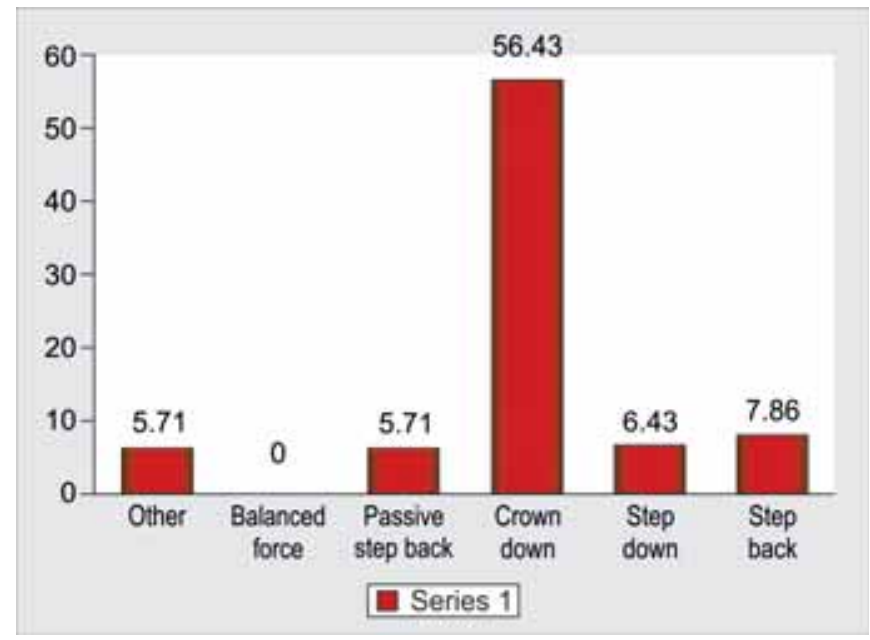

Fig. 2: What is the best method for preparation of these canals?

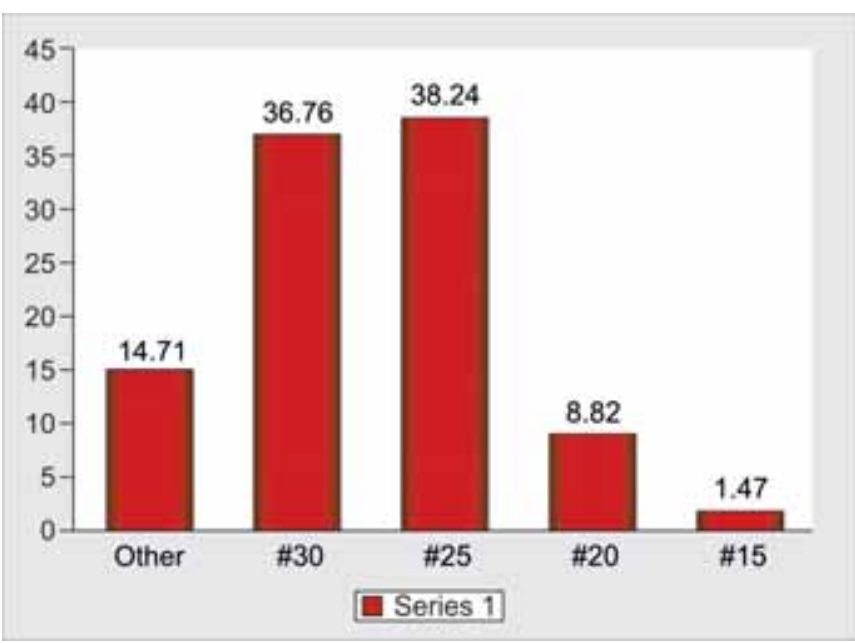

Fig. 3: What is the best size of master apical file (MAF) for preparation of these canals?

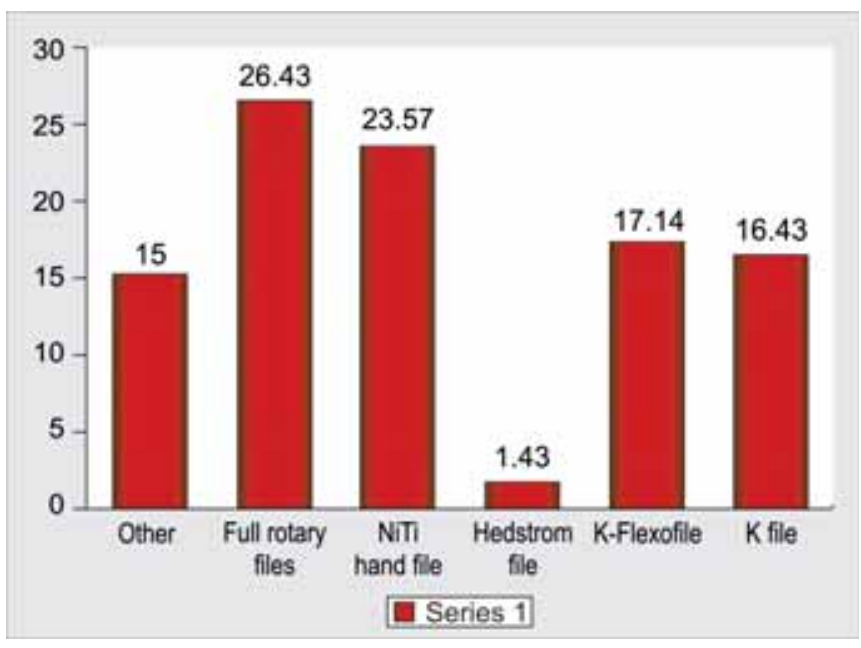

Fig. 4: Which kind of instruments do you use in preparation of these canals?

$2 \%$ reaming and the others none of them. There was a significant difference between watch-winding motion and other choices $(\mathrm{p}=0)$.

11. Can full rotary instruments be used through the entire length of the canal?

Fifty-three percent of respondents answered negatively to this question. There was no significant difference between this choice and the positive response $(\mathrm{p}>0.05)$.

12. What is the best method of inserting calcium hydroxide in these canals?

Thirty-eight percent of respondents chose the injection method for replying to this question. Thiry-one percent considered the file as the best method, 19\% lentulo, 4\% master cone and $6 \%$ other methods. There was a significant difference between the injection method and other choices $(\mathrm{p}=0)$.

13. What is the best method for obturation of these canals? Thirty-seven percent of respondents believed that a thermoplasticized technique is the best method for obturation of dilacerated canals. It was a significant difference between this choice and other choices $(\mathrm{p}=0)$ (Fig. 5).

14. Which kind of spreaders do you use in obturation of these canals?

Fifty percent of respondents preferred nickel-titanium (NiTi) spreaders for obturation of these canals. Twentysix percent of respondents used stainless steel spreaders and $23 \%$ of respondents did not use spreaders. There was a significant difference between NiTi spreaders and other choices $(p=0)$.

15. Is the prognosis of the treatment of these canals lower than normal canals?

Seventy-one percent of the ABE members stated that the prognosis of the treatment of these canals is not lower than normal canals, whereas $29 \%$ had the opposite opinion ( $\mathrm{p}=0)$. 


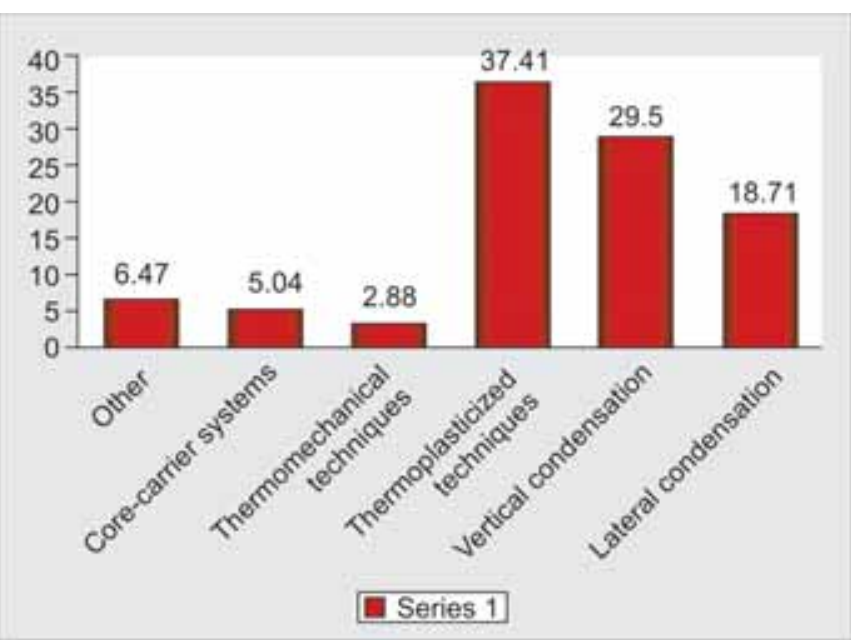

Fig. 5: What is the best method for obturation of these canals?

\section{DISCUSSION}

The purpose of this survey was to gather data from diplomates of the $\mathrm{ABE}$ regarding definition and endodontic treatment of dilacerated canals. This is the first survey collecting data regarding this important topic in endodontics.

One of the most important aims in this survey was to obtaining a precise definition for dilacerated canal. The most acceptable response was $>40^{\circ}$ for considering a curvature as dilaceration; however, one of the respondents stated that dilaceration is determined by radius of curvature not degrees of curvature. Two diplomates stated that they consider a double curve or $\mathrm{S}$ curve to be dilacerated, not a simple severe curve.

An important problem in endodontic treatment of these teeth is the difficulty to continuously follow the canal curvature, which may result in preparation errors, such as block or ledge, apical transportation, zipping, perforation and instrument breakage. ${ }^{10,11}$ Most of the ABE diplomates felt that transportation is the most likely complication in preparation of these canals. For prevention of transportation, the flexibility of the instruments with respect to their size must be considered. Also, NiTi hand instruments and instruments with noncutting tips, such as Flex-R, may be helpful for maintaining the original curvature. An important point seems to be regarding precurving. Precurving has its role for initial negotiation if there is an obstruction or natural impediment. This is important for small files. For larger files, precurving is mainly done in an attempt to more evenly distribute forces and thus reduce the chance of straightening.

The outcome of root canal therapy depends on complete biomechanical debridement and elimination of microorganisms from the canal, ${ }^{12}$ so a multivisit approach may be generally recommended. However, most of the ABE diplomates preferred one-visit approach for treating dilacerated canals. If multivisit approach should be considered in order to overcome the complexity of reaching calcium hydroxide to the apical third of dilacerated teeth, it has been proposed to mix calcium hydroxide with glycerin rather than with sterile water. ${ }^{13}$ In this survey, most of respondents stated that injection method is the best methods of inserting calcium hydroxide in these canals. Although some previous researches on nondilacerated canals are in agreement with this, ${ }^{14,15}$ it is not in line with some other publications that see the lentulo as better. ${ }^{16-18}$ In contrast with these, four diplomates stated that calcium hydroxide should not be inserted in dilacerated canals because placing an interim material such as calcium hydroxide in an extremely dilacerated canal will lead to inability to completely remove the material and therefore to an incomplete seal.

Central to successful endodontic treatment is a thorough knowledge, respect and appreciation for root canal anatomy together with careful, thoughtful and meticulously performed cleaning and shaping procedures. ${ }^{10}$ Most of respondents considered the root canal preparation as the most difficult step in treating these canals.

Direct access to the apical foramen is an important benefit gained through the access cavity preparation. In order to provide the most direct access possible to the apical foramen, enough tooth structure must be removed to allow the endodontic instruments to be moved freely within the coronal cavity. A modified outline form to accommodate the instrument unrestrained in the severely curved canals. ${ }^{19}$ In this survey, most of diplomates felt that access cavity preparation needs modification in dilacerated teeth; however, there was no significant difference between positive response group and negative ones.

There is no published research regarding the best way of working length determination in dilacerated canals; however, this survey showed that apex locator may be the best choice.

The possibility of apical transportation and blockage would be increased by apicocoronally instrumentation techniques. Most of respondents chose crown-down technique as the best method for preparing these canals. However, one ABE diplomate believed that the technique is predicated on the design of the rotary instrument and the techniques of using that instrument. In addition, depending on the ability of that instrument to achieve working length, may impact the strategy employed. In other words, sometimes multiple passes with the instruments may be necessary to achieve the desired canal enlargement. By doing this it employs lower tortional forces on the instruments.

Most of respondents to this survey stated that MAF \#25 is the best size. Four diplomates believed that apical foramen 
of dilacerated canals is not smaller than straight canals, so it should be at least \#35. One of the authors (HJ) has a project for determining the best size of MAF for ending the apical preparation of these canals.

Although most of respondents stated the full rotary instruments cannot be used through entire working length of dilacerated canals, in another question, many of them stated that they use full rotary files for preparation of these canals. Also, most of respondents prefer the watch-winding instrument system for instrumentation of these canals that had significantly difference from other choices.

Although lateral compaction of curved canals can be very effective in most teeth, this technique may be very difficult in dilacerated canals. If small, flexible spreaders cannot reach to within $1 \mathrm{~mm}$ of the working length, or the taper of the root canal preparation is less than that of the spreader, then lateral compaction is not the technique of choice. ${ }^{19}$ If the lateral compaction technique is chosen, then spreaders made from NiTi are highly recommended for the filling of severely curved root canal systems, ${ }^{10}$ since they will penetrate to greater depths and distribute forces more evenly than stainless steel spreaders. The use of warm or thermoplasticized gutta-percha techniques may be more applicable in many cases, although these techniques may also be difficult to perform because of the presence of the dilacerations. ${ }^{19}$ Some studies have shown that in curved canals, ThermaFil (Tulsa Dental Products, Tulsa, Okla) results in comparable to ${ }^{20}$ or better apical seal than lateral condensation technique; $;^{21,22}$ however, Barkins and Montgomery ${ }^{23}$ did not agree with this idea. In this survey, most of respondents chose a thermoplasticized technique as the best one for obturation of dilacerated canals. Also, half of respondents preferred $\mathrm{NiTi}$ spreaders for obturation of these canals, if they want to use lateral condensation technique.

The prognosis of dilacerated teeth that require endodontic treatment varies according to the severity of the deformity and the practitioner's skills. ${ }^{19,24,25}$ It will also depend on many other factors, such as the reason why endodontic treatment was required and how much tooth structure remains. Most of the ABE diplomates stated that the prognosis for endodontic treatment of these canals is not lower than normal ones.

We surveyed diplomates of the ABE, which is the only certifying board in endodontics recognized by the AAE. The ABE diplomates have a high level of training and clinical proficiency. Surveying other groups in specialty of endodontics may be helpful and may result in different results.

\section{CONCLUSION}

A crown-down technique for root canal preparation and a thermoplastic obturation technique are recommended for canals, their curvature is more than $40^{\circ}$. The prognosis of the treatment of these canals is judged not lower than normal canals.

\section{CLINICAL SIGNIFICANCE}

Crown-down technique and thermoplastic obturation are recommended for dilacerated canals.

\section{ACKNOWLEDGMENT}

This work was supported in part by the Vice Chancellor for Research of Mashhad University of Medical Sciences. The authors would like to thank all scientific members of Mashhad Faculty of Dentistry for their participation in the process of evaluating validity and reliability of the questionnaire. Also, their sincere thanks to all ABE diplomates participated in this survey.

They also thank Prof Paul A Rosenberg from the University of New York and Dr Ali Bagherpoor from the Mashhad Faculty of Dentistry for their kind help in preparing the questionnaire and for their beneficial comments.

\section{REFERENCES}

1. Jafarzadeh H, Abbott PV. Dilaceration: Review of an endodontic challenge. J Endod 2007;33:1025-30.

2. Tomes J. A course of lectures on dental physiology and surgery (lectures I-XV). London 1846-48.

3. Shafer WG, Hine MK, Levy BM. A textbook of oral pathology (4th ed). Philadelphia: WB Saunders 1983;40:308-11.

4. Tiecke RW. Pathologic physiology of oral disease. St Louis: Mosby 1959.

5. Moreau JL. "Scorpion tooth" or dilaceration of the central incisor. Chir Dent Fr 1985;55:53-55.

6. Udoye CI, Jafarzadeh H. Dilaceration among Nigerians: Prevalence, distribution, and its relationship with trauma. Dent Traumatol 2009;25:439-41.

7. Malcic A, Jukic S, Brzovic V, Miletic I, Pelivan I, Anic I. Prevalence of root dilaceration in adult dental patients in Croatia. Oral Surg Oral Med Oral Pathol Oral Radiol Endod 2006;102:104-09.

8. Hamasha AA, Al-Khateeb T, Darwazeh A. Prevalence of dilaceration in Jordanian adults. Int Endod J 2002;35:910-12.

9. Chohayeb AA. Dilaceration of permanent upper lateral incisors: Frequency, direction, and endodontic treatment implications. Oral Surg Oral Med Oral Pathol 1983;55:519-20.

10. Hargreaves KM, Cohen S. Pathways of the pulp (10th ed). St Louis: Mosby 2011.

11. Walton RE, Torabinejad M. Principles and practice of endodontics (2nd ed). Philadelphia: WB Saunders 1996;330-32.

12. Seltzer S. Endodontology. Biologic considerations in endodontic procedures. New York: McGraw-Hill 1971;386.

13. Rivera EM, Williams K. Placement of calcium hydroxide in simulated canals: Comparison of glycerin versus water. J Endod 1994;20:445-48.

14. Oztan MD, Akman A, Dalat D. Intracanal placement of calcium hydroxide: A comparison of two different mixtures and carriers. 
Oral Surg Oral Med Oral Pathol Oral Radiol Endod 2002;94: 93-97.

15. Deveaux E, Dufour D, Boniface B. Five methods of calcium hydroxide intracanal placement: An in vitro evaluation. Oral Surg Oral Med Oral Pathol Oral Radiol Endod 2000;89: 349-55.

16. Peters CI, Koka RS, Highsmith S, Peters OA. Calcium hydroxide dressings using different preparation and application modes: Density and dissolution by simulated tissue pressure. Int Endod J 2005;38:889-95.

17. Torres CP, Apicella MJ, Yancich PP, Parker MH. Intracanal placement of calcium hydroxide: A comparison of techniques, revisited. J Endod 2004;30:225-27.

18. Sigurdsson A, Stancill R, Madison S. Intracanal placement of $\mathrm{Ca}(\mathrm{OH})_{2}$ : A comparison of techniques. J Endod 1992;18: 367-70.

19. Ingle JI, Bakland LK, Baumgartner JC. Ingle’s Endodontics (6th ed). London: BC Decker Inc 2008.

20. Schafer E, Olthoff G. Effect of three different sealers on the sealing ability of both thermafil obturators and cold laterally compacted Gutta-Percha. J Endod 2002;28:638-42.

21. Lares C, elDeeb ME. The sealing ability of the Thermafil obturation technique. J Endod 1990;16:474-79.

22. Leung SF, Gulabivala K. An in vitro evaluation of the influence of canal curvature on the sealing ability of thermafil. Int Endod J 1994;27:190-96.

23. Barkins W, Montgomery S. Evaluation of Thermafil obturation of curved canals prepared by the canal Master-U system. J Endod 1992;18:285-89.

24. Neville BW, Damm DD, Allen CM, Bouquot JE. Oral and maxillofacial pathology (2nd ed). Philadelphia: WB Saunders 2002;86-88.
25. Jafarzadeh H, Abbott PV. Ledge formation: Review of a great challenge in endodontics. J Endod 2007;33:1155-62.

\section{ABOUT THE AUTHORS}

\section{Nafiseh Dastmalchi}

Student, Department of Endodontics, Faculty of Dentistry, Dental Research Center, Mashhad University of Medical Sciences Mashhad, Iran

\section{Zeinab Kazemi}

Student, Department of Endodontics, Faculty of Dentistry, Dental Research Center, Mashhad University of Medical Sciences Mashhad, Iran

\section{Siroos Hashemi}

Student, Department of Endodontics, Faculty of Dentistry, Dental Research Center, Mashhad University of Medical Sciences, Mashhad, Iran

\section{Ove A Peters}

Professor, Department of Endodontics, Arthur A Dugoni School of Dentistry, University of the Pacific, USA

\section{Hamid Jafarzadeh (Corresponding Author)}

Assistant Professor, Department of Endodontics, Faculty of Dentistry Dental Research Center, Mashhad University of Medical Sciences Mashhad, PO Box: 91735-984, Iran, e-mail: hamid_j365@yahoo.com jafarzadehBH@mums.ac.ir 